\title{
Impact of electric locomotive traction of the passenger vehicle Ride quality in longitudinal train dynamics in the context of Indian railways
}

\author{
Sunil Kumar Sharma ${ }^{1, a}$ AND Anil Kumar ${ }^{2}$ \\ 1 Centre for Transportation Systems, Indian Institute of Technology Roorkee, India \\ 2 Department of Mechanical and Industrial Engineering, Indian Institute of Technology Roorkee, India
}

Received 9 November 2015, Accepted 12 July 2016

\begin{abstract}
Rail transport is one of the major modes of transportation in India. The dynamic performance of a railway vehicle, in terms of serviceability and safety, was evaluated on the basis of specific performance indices such as ride quality and comfort. This paper is an attempt to analyse the longitudinal dynamic model of the passenger train for the attainment of better vehicle ride quality and comfort. The modelling has been done in two phases: in the first phase, a mathematical model was analysed which was further used for the evaluation of the longitudinal dynamic forces that appear on the buffer, draw gear and fastening devices during the braking process. The second phase includes simulation of longitudinal train dynamics considering the effects of forces like rolling resistance, brake force, coupler force and the gravitational force acting externally on a vehicle for better ride quality and comfort in comparison to the traction effect on WAP-5 and WAP-7 Indian locomotives. The Sperling ride index and ISO 2631 were used respectively to calculate the ride quality and comfort using filtered RMS accelerations. Simulation results revealed that WAP-5 was better at an initial speed of $30 \mathrm{~km} \cdot \mathrm{h}^{-1}$ and $45 \mathrm{~km} \cdot \mathrm{h}^{-1}$, whereas, the WAP-7 gave better ride quality and comfort than WAP-5 at and above the speed of $60 \mathrm{~km} \cdot \mathrm{h}^{-1}$.
\end{abstract}

Key words: Longitudinal vehicle dynamics / traction force / sperling ride index / dynamic behaviour / ride quality / ride comfort

\section{Introduction}

The efficient working of Indian Railways is dependent on various factors which include safety parameters along with the efficiency of its locomotive which is responsible for the rapid acceleration of the train, and also its braking system which enables the train to bring it to a standstill at the station, even on an adverse gradient.

Electric engines are the lightweight locomotive vehicles that constitute mainly motors and wheel axles. In comparison to a diesel engine, an electric engine has almost no moving parts, therefore, electric engines are easier to maintain. Moreover, due to the light weight, the engines resulted in less wear and tear of the railway tracks [1]. The electric engine draws power from overhead equipment and requires only a transformer and regulator to convert the power into the operational level. Currently, the electric locomotives used by Indian Railway (IR) for passenger transports are broad gauge $\mathrm{AC}$ traction motive

\footnotetext{
${ }^{\mathrm{a}}$ Corresponding author: sunilsharmaiitr@gmail.com
}

power passenger service locomotives (WAP), i.e. WAP- 4, WAP- 5, WAP- 7 series [1].

IR is contemplating to lay exclusive passenger corridors for movement of semi-high speed trains. It is also planned to upgrade the speed of passenger trains upto $150 \mathrm{~km} \cdot \mathrm{h}^{-1}$ on existing tracks and $200 \mathrm{~km} \cdot \mathrm{h}^{-1}$ on proposed passenger corridors [2]. For this, Research Design and Standards Organisation (RDSO) conducted a test trail with 24-coach 1430 tonne passenger rake for acceleration and deceleration rate [1]. The trail concluded that WAP-7 can accelerate faster than the WAP-5, but the vehicle ride quality was not observed. This led to the emergence of a specific issue, i.e. which locomotive provides better stability and comfort at various speeds. Thus, the ride stability and comfort becomes a topic to identify the ride quality and comfort at various speed. This analysis examines the comfort level of passengers caused due to changes in the movement of a vehicle's longitudinal direction, viz. travelling direction. Per contra, the limitation while operating a vehicle network at high velocity, high capacity and short trip times might affect passenger 
S.K. Sharma and A. Kumar: Mechanics \& Industry 18, 222 (2017)

Table 1. Details of the two electric locomotives $[1,3,4]$.

\begin{tabular}{|c|c|c|}
\hline Electric locomotive & WAP-5 & WAP-7 \\
\hline $\begin{array}{l}\text { Traction } \quad \text { Mo- } \\
\text { tors(TM) }\end{array}$ & $\begin{array}{l}\text { ABB's 6FXA } 7059 \text { 3-phase squirrel cage } \\
\text { induction motors }(1,583 / 3,147 \mathrm{rpm} \text {, } \\
2,180 \mathrm{~V}, 1,150 \mathrm{~kW}, 370 / 450 \mathrm{~A}) \text {. Torque } \\
6,930 / 10,000 \mathrm{Nm} \text {, partially suspended, } \\
\text { Forced-air ventilation, Weight } 2,050 \mathrm{~kg} \text {, } \\
96 \% \text { efficiency }\end{array}$ & $\begin{array}{l}\text { 6FRA } 60683 \text {-phase squirrel-cage induc- } \\
\text { tion motors }(2,180 \mathrm{~V}, 850 \mathrm{~kW}, 1,283 / 2,484 \\
\text { rpm, } 270 / 310 \mathrm{~A}) \text {. Torque } 6,330-7,140 \mathrm{Nm} \text {, } \\
\text { nose suspended, axle-hung, forced air ven- } \\
\text { tilation, Weight- } 2,100 \mathrm{~kg}, 95 \% \text { efficiency }\end{array}$ \\
\hline Gear Ratio & $67: 35: 17$ & $72: 20$ \\
\hline Axle load (tons) & $19.5 \mathrm{t}$ & $20.5 \mathrm{t}$ \\
\hline Power & Max: $6,000 \mathrm{hp}(4,474 \mathrm{~kW})$ & Max: $6,350 \mathrm{hp}(4,740 \mathrm{~kW})$ \\
\hline Tractive effort & Max: $258 \mathrm{kN}$ & Max: $323 \mathrm{kN}$ \\
\hline Wheel diameter & New: 1,092 mm, Full-worn: 1,016 mm & New: 1,092 mm, Full worn: 1,016 mm \\
\hline Bogies & Bo-Bo, Henschel Flexifloat & Co-Co, Fabricated Flexicoil Mark IV \\
\hline $\begin{array}{l}\text { locomotive weight } \\
\text { (tons) }\end{array}$ & $78 \mathrm{t}$ & $123 \mathrm{t}$ \\
\hline Braking & Air Braking & Air Braking \\
\hline Train coupling & Central Buffer Couplers & Central Buffer Couplers \\
\hline
\end{tabular}

intolerance due to high longitudinal acceleration. Thus, it implies that the tolerance limit of passengers towards the longitudinal acceleration will have an impact on the design of the vehicle braking and traction system.

In this paper, a comparative study of WAP -5 and WAP-7 electric locomotives considering a double decker train of 14 coaches using a universal mechanism (UM) on Mumbai-Ahmedabad rail route in India is presented. In this analysis, calculation of the acceleration of train in the longitudinal direction is done while keeping all other parameters constant. Moreover, the ride quality and comfort were evaluated using the Sperling ride index and ISO 2631-1997, respectively. For this analysis, different initial speeds, i.e. $30,45,60,90,120,150$ and $180 \mathrm{~km} . \mathrm{h}^{-1}$ were taken into consideration. The details of the locomotives were given in Table 1.

\section{Mathematical modelling of longitudinal train dynamics (LTD)}

\subsection{Longitudinal model of the train}

A coach running on track was subjected to the following types of forces which exert longitudinally in the train. Figure 1 shows the model of a train as a cascade composition of mass points in the longitudinal direction.

The mechanical behaviour of the vehicle was simulated according to a quite efficient mono-dimensional model of the train which was developed in prior researches $[5-7]$ and is explained by Equation (1) that characterizes the motion of the vehicle as Newton's second law of motion: where for the $i$ th vehicle the force relationship is developed. $x_{i}=$ the longitudinal displacement of the $i$ th vehicle and $x_{i-1}, x_{i+1}=$ longitudinal displacement of the fore and aft vehicle, respectively.

$m_{i} \ddot{x}_{i}= \pm F_{c w(l e a d)} \pm F_{c w(t r l)_{i}}-F_{b r k_{i}} \pm F_{t / d b} \pm F_{\text {grad }_{i}}-F_{r r_{i}}$
On each vehicle mass $\left(m_{\mathrm{i}}\right)$ which forms the train at a speed of $v$, the following forces act: inertial force, braking force $F_{b r k_{i}}$, resistance to motion $F_{r r_{i}}$, grade resistance $F_{\text {rad }_{i}}$, traction or braking effort $F_{t / d b}$ and finally the force from the buffer and draw gear device, i.e. coupler force from leading coach $F_{c w(l e a d)}$ and trailing coach $F_{c w(t r l)_{i}}$.

The solution to the Equation (1) describes that the movement of vehicles during emergency braking is obtained by numerical integration using an original calculator program elaborated in MATLAB [8] for a time period of $t=10 \mathrm{~s}$. Thus, determination of the state variables of the system, i.e. the the displacement and the relative velocity between vehicles can be done. Further, the forces developed in the buffers and traction devices can be calculated. For this purpose, it is necessary to first calculate the resistances to the motion and braking forces.

Taking into consideration the vehicle $i$ th, the resistance to motion is determined by the formula in Equation $(2)[9,10]$.

$$
F_{r r_{i}}=m_{i} g r_{v i}
$$

where, $r_{v i}$ represents the specific resistance to motion of the $i$ th vehicle and $g$ gravitational acceleration. It should be specified that the resistance to motion is a characteristic specific for each type of vehicle, which is calculated using empirical formulas, as follows in Equation (3) [11].

$$
r_{v i}=f(v)
$$

Locomotive (WAP 7): $0.754+0.00933 v+0.00002641 v^{2}$

Locomotive (WAP 5): $1.34819+.02153 v+0.00008358 v^{2}$

Passenger (LHB): $1.43+0.0054 v+0.000253 v^{2}$

As for the braking force, the vehicle was equipped with axle mounted disc brakes in order to have an effective brake power to halt the train within the emergency braking distance. The brake forces were acted on the discs fitted on the axles. Therefore, the braking force is calculated using Equation (4) [10]. 


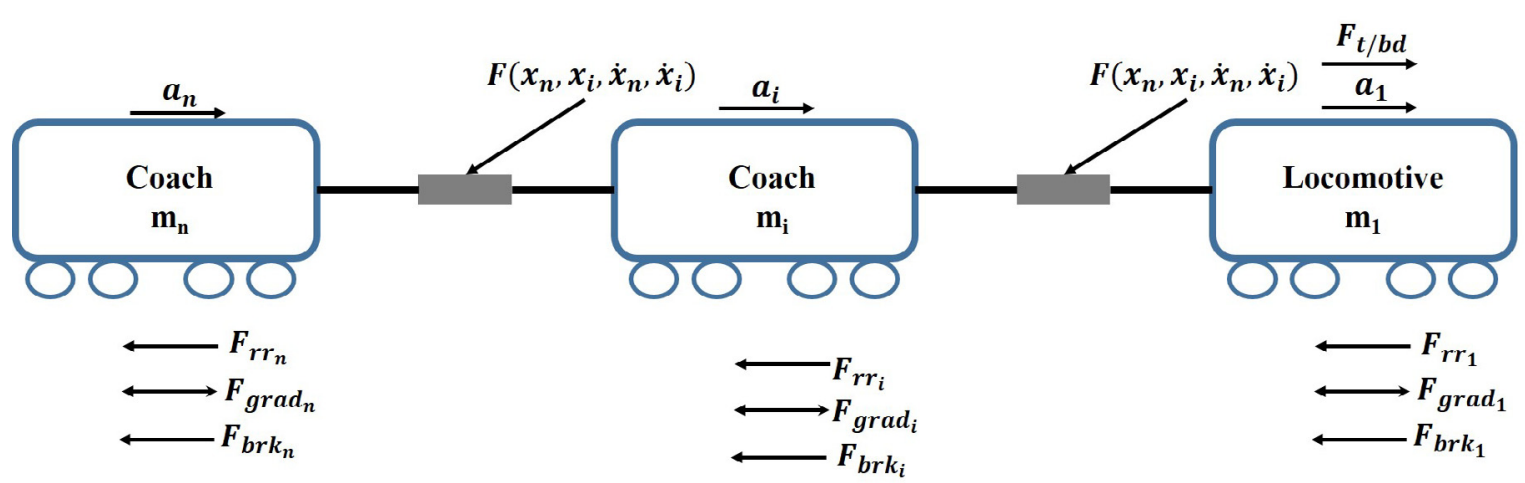

Fig. 1. Longitudinal model of the train $[5,6]$.

Table 2. Brake modelling parameter.

\begin{tabular}{cc}
\hline Parameter & Description \\
\hline$d_{b c}$ & Brake cylinder diameter $(254.8 \mathrm{~mm})$ \\
$F_{s R}$ & Release spring force $(1.3 \mathrm{kN})$ \\
$D_{o}$ & Wheel diameter $(1092 \mathrm{~mm})$ \\
$r_{m}$ & Medium friction radius $(588 \mathrm{~mm})$ \\
$n_{b c}$ & Number of brake cylinders of the vehicle (i.e. locomotive (8) and coaches $(2))$ \\
$\mu_{d}$ & The friction coefficient between discs and pads $(0.35)$ \\
$\eta_{b r}$ & Mechanical efficiency of the brake rigging $(95 \%)$ \\
$i_{t}$ & Amplification ratio $(1.954)$ \\
\hline
\end{tabular}

The air brake force

$$
F_{b r k(i)}=\left(\left(\frac{\pi d_{b c}^{2}}{4}\right) \eta_{c y l} p_{\max (i)}-F_{s R}\right) i_{t} n_{b c} \frac{2 \mathrm{r}_{m}}{D_{0}} \mu_{d} \eta_{b r}
$$

Brake modeling parameters is listed in Table 2.

Finally, The couplers used on LHB coaches are tight lock center buffer couplers of AAR type H [12]. The connection between two contiguous coaches within a train is maintained by a "Coupler System" which consists of a tight lock coupler head (AAR type $\mathrm{H}$ ) with drawbar, drawbar guide (support) and draft gear (draw and buffing gear). The draft gear plays a very crucial role by absorbing the superfluous energy in both draw and buff mode. The draft gear consists of elastic elements and friction springs, thus are able to transmit both the tensile and compressive forces. The modelling for coupler system consisting elastic and friction element in the buffer and draw gear has also been studied by Crăciun and Mazilu [9].

Hence, mathematical modelling for draft gear is mainly aimed to establish a relation between the coupler forces and its relative displacement, in the course of train braking. These forces depend on the variation of relative displacement and relative velocity due to the rigidity of elastic elements, as well as the damping degree. In under mentioned Equation (5), $k_{a}$ is a constant which depends on upon the elasticity of the material and $k_{f r}$ which is a frictional spring constant, i.e. a function of the friction between the inner and outer rings [12,13]. Moreover, the coupler system consists of a tight lock at the coupler head and it is subjected to a preload for holding the adjacent coupler head which is here denoted by $P$. Thus, the following Equation (5) is used to evaluate the coupler forces $(5)$.

$F_{c w}(x, \dot{x})= \begin{cases}k_{a b} x+k_{f r b}\left|x_{i}\right| \tanh (u . \dot{x})+P & \text { for } x<0, \\ P & \text { for } \quad x=0, \\ k_{a d} x+k_{f r d}\left|x_{i}\right| \tanh (u . \dot{x})+P & \text { for } \quad x>0\end{cases}$

In Equation (5), the relative displacement of the stroke in the draft gear is represented as $x$ and $\dot{x}$ its relative velocity. This Equation (5) is used to compute the characteristics of the draft gear as shown in Figure 2. If the relative displacement, $x<0$ the coupler assembly is in compression (buff), whereas if the relative displacement, $x=0$ then the coupler assembly is in preload tensile condition. Likewise, if the relative displacement is greater than $0(x>0)$, the coupler assembly is in tensile mode (draw gear).

For performing simulation, the main parameters used for buffers are $P=25 \mathrm{kN}, k_{\mathrm{ab}}=11785 \mathrm{kN} \cdot \mathrm{m}^{-1}, k_{\mathrm{frb}}=$ $5457 \mathrm{kN} \cdot \mathrm{m}^{-1}$ and for draw gear $k_{\mathrm{ad}}=9430 \mathrm{kN} \cdot \mathrm{m}^{-1}$, $k_{\text {frd }}=4365 \mathrm{kN} \mathrm{m}^{-1}$. To maintain the standard, the model must meet the following characteristics: the static impedance should be $\leq 1600 \mathrm{kN}$ (maximum), capacity $\leq 35 \mathrm{~kJ}$ and the damping factor ought to be $\geq 60 \%$ [13]. The respective coupler forces yielded the static impedance force of the buff and draw gear as shown in Figures 2a and $2 \mathrm{~b}$.

Following is the outcome as given in Table 3 of various initial velocities taken into consideration under buff and draw gear mode. 


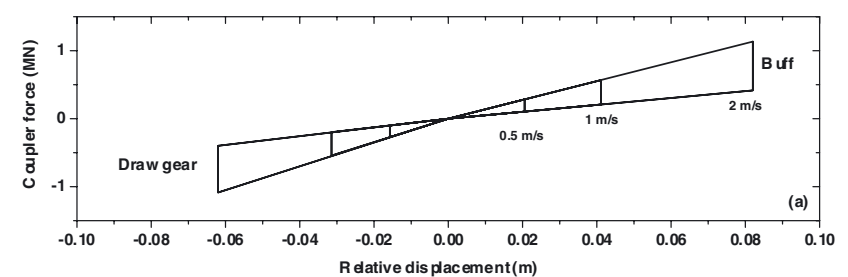

(a)

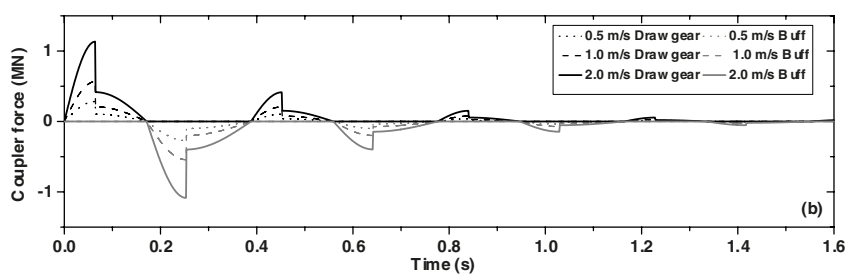

(b)

Fig. 2. (a) Force-displacement characteristic of the coupler. (b) Buffer and draw gear force time history for $0.5,1.0$ and $1.5 \mathrm{~m} . \mathrm{s}^{-1}$ initial velocity.

Table 3. Effect of initial velocity in the coupler force and displacement.

\begin{tabular}{cccc}
\hline Initial velocity $\left({\left.\mathrm{m} . \mathrm{s}^{-1}\right)}^{-}\right.$ & Mode & Displacement $(\mathrm{m})$ & Coupler Force $(\mathrm{kN})$ \\
\hline \multirow{2}{*}{0.5} & Buff & 0.020 & 283.6 \\
& Draw gear & 0.015 & 271.2 \\
\hline \multirow{2}{*}{1} & Buff & 0.041 & 567.1 \\
& Draw gear & 0.031 & 542.6 \\
\hline \multirow{2}{*}{2} & Buff & 0.081 & 1134.5 \\
& Draw gear & 0.060 & 1085.2 \\
\hline
\end{tabular}

\subsection{Traction modules}

Tractive effort (TE) is the force generated by a locomotive in order to generate motion through tractive force and braking effort (BE). It is a measure of the braking power of a vehicle. Nevertheless, the behaviour of locomotives was independent and it was necessary to control that kind of behaviour in relation to speed, time, and position. TE and BE were evaluated experimentally by RDSO [14] as shown in Figures $3 \mathrm{a}$ and $3 \mathrm{~b}$ and the same were taken for the analysis in Universal Mechanism. Thus, to have versatility in the module, the force gradient during traction implementation and removal could also be coerced and lastly, the entire power was exposed to the linear variation from zero to maximum power [6]. Moreover, TE/BE also depends on various factors which include horsepower of the electric engine, the ability of the main generator, the ability of traction motors, gear ratio and adhesion (weight on driving wheels, rail condition, wheel slip control system, and inverter system).

\subsection{Autocorrelation coefficient function}

The autocorrelation coefficient function is a mathematical phenomenon which is considered for evaluating the randomness of the signal. Randomness is calculated by computing autocorrelation for data values at different time lags. Its value (results) predict randomness, then in such case, the value of autocorrelation must be close to zero for each and every time-lag separations. If it is non-random, then the value of its autocorrelations would be significant at non-zero. However, for a signal $f(t)$ as our random forcing function, along the time axis, an average value of the product $f(t) f(t+\tau)$ is given by Equation (6) [15].

$$
R_{f f}(\tau)=\lim _{x \rightarrow \infty} \frac{1}{T} \int_{\frac{-T}{2}}^{T} f(t) f(t+\tau) \mathrm{d} t
$$

From the above-mentioned Equation (6), the quantity $R_{f f}(\tau)$ is always a real-valued even function with a maximum occurring at $\tau=0$, was a so-called random auto-correlation function. In physical terms, the autocorrelation function gives the relationship which explains the dependency of a particular instantaneous amplitude value of the random time signal on the previous occurring amplitude value. A random process is said to have an idealistic condition, the autocorrelation function comprises of a $\delta$ function at $\tau=0$. The new function, $R_{f f}(\tau)$, which is even, real-valued, goes to zero as $\tau$ becomes large (both positively and negatively) and obeys the Dirichlet condition given in Equations (7) and (8) [16].

$$
\begin{aligned}
R_{f}(\infty) & =[\bar{f}(t)]^{2} \\
\bar{f}(t) & =\sqrt{R_{f}(\infty)}
\end{aligned}
$$

The mean value of $f(t)$ is equal to the positive square root of the autocorrelation as the time displacement becomes very long. Autocorrelation plots were obtained by vertical axis: autocorrelation coefficient is given by Equation (9) [15].

$$
\begin{aligned}
R_{h} & =c_{h} / c_{0} \\
c_{h} & =\frac{1}{N} \sum_{t-1}^{N-h}\left(f_{t}-\bar{f}\right)\left(f_{t+h}-\bar{f}\right) \\
c_{0} & =\sum_{t=1}^{N}\left(f_{t}-\bar{f}\right)^{2} / N
\end{aligned}
$$

where $c_{0}$ is variance function, $R_{h}$ was between -1 and +1 and $N$ is the sample size and on the horizontal axis, there 


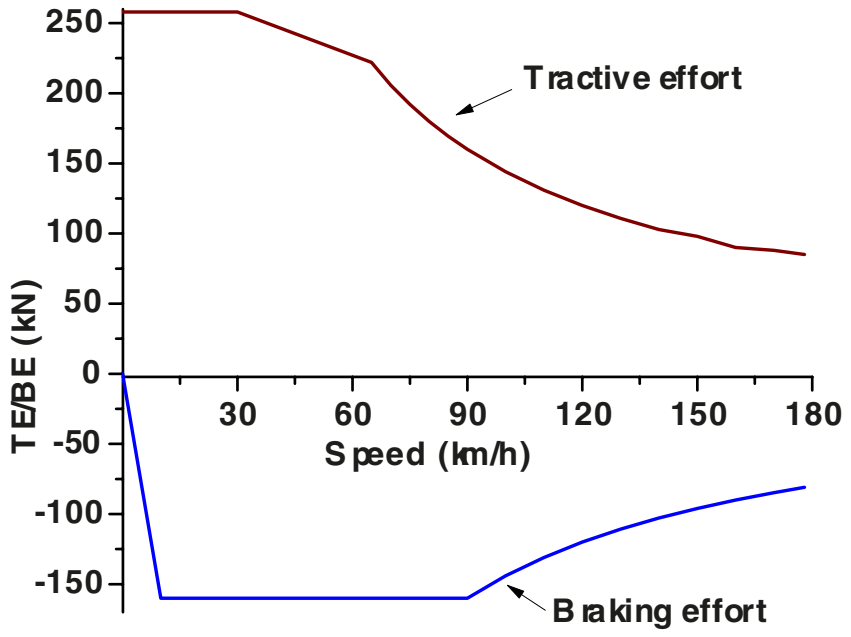

(a)

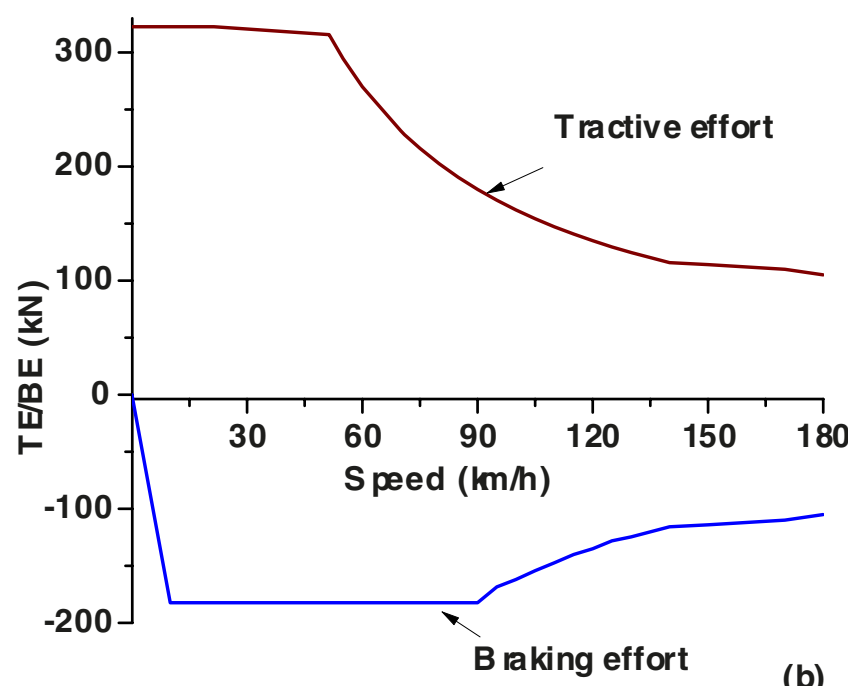

(b)

Fig. 3. (a), (b): TE/BE v/s Speed forWAP-5, WAP-7 locomotive respectively [14].

Table 4. Ride quality evaluation scales [17]

\begin{tabular}{cc}
\hline Ride quality & Ride index $\left(W_{z}\right)$ \\
\hline Dangerous & 5 \\
Not acceptable for running & 4.5 \\
Acceptable for running & 4 \\
Satisfactory & 3 \\
Good & 2 \\
Very good & 1 \\
\hline
\end{tabular}

will be time lag $(h=1,2,3 \ldots)$ and $c_{h}$ is auto covariance function.

\subsection{Sperling ride quality index}

Sperling proposed a ride index and developed the socalled Wz method (Werzungzahl). $W z$ was the frequency weighted r.m.s value of the different accelerations evaluated over defined time intervals or over a defined track section. For an arbitrary acceleration signal, which was not necessarily a harmonic signal, the frequency-weighted root mean square value of accelerations $\left(a^{\text {wrms }}\right)$ should be used. The original mathematical expression, introduced by Sperling is given in Equation (12) [17].

$$
W_{z}=4.42\left(a^{w r m s}\right)^{3 / 10}
$$

The rail vehicle was accessed on Sperling's ride evaluation scales mentioned in Table 4, in order to judge the ride quality.

\subsection{ISO 2631:1997 for Ride comfort}

ISO 2631 provides basic and additional evaluation method based on the crest factor. Moreover, ISO 26311 Section 6 specifies an r.m.s. based method for evaluation of ride comfort [18]. The weighted r.m.s. acceleration $\left(a_{w}(t)\right.$ in $\left.\mathrm{m} . \mathrm{s}^{-2}\right)$ of a discrete time-domain signal is given in Equation (13).

$$
a_{w}=\left[\frac{1}{T} \int_{0}^{T} a_{w}^{2}(t) \mathrm{d} t\right]^{\frac{1}{2}}
$$

The standard defines the total vibration value of weighted r.m.s. acceleration for all directions in the respective position. At present, however, in that analysis only the longitudinal direction was considered. As per ISO-2631, Table 5 gives approximate indications of likely reactions to various magnitudes of overall vibration values in public transport.

\section{Multibody modeling of WAP-5 and WAP-7 for LTD}

LTD modelling was done by considering no effect of the vertical or the lateral movement of the vehicle. Based on these assumptions, the forces which were taken into consideration in the train includes traction forces, air brake forces, in-train forces (coupler forces), dynamic brake forces, gravitational component, curving resistance and propulsion resistance. However, in the modelling of the passenger train connection systems air brake forces and in-train forces were probably the two most difficult task in LTD simulations [5].

\subsection{Train modelling}

The train model consists of a locomotive, i.e. WAP7 and WAP-5, double-decker coaches, generator/luggage van and in train connection called AAR "H"' Type Tight 
Table 5. Ride comfort measure for r.m.s acceleration measuring level.

\begin{tabular}{cc}
\hline Perception & r.m.s acceleration vibration level \\
\hline Extremely uncomfortable & Greater than $2 \mathrm{~m} . \mathrm{s}^{-2}$ \\
Very uncomfortable & $1.25 \mathrm{~m} . \mathrm{s}^{-2}$ to $2.5 \mathrm{~m} . \mathrm{s}^{-2}$ \\
Uncomfortable & $0.8 \mathrm{~m} . \mathrm{s}^{-2}$ to $1.6 \mathrm{~m} . \mathrm{s}^{-2}$ \\
Fairly uncomfortable & $0.5 \mathrm{~m} . \mathrm{s}^{-2}$ to $1 \mathrm{~m} . \mathrm{s}^{-2}$ \\
A little uncomfortable & $0.315 \mathrm{~m} . \mathrm{s}^{-2}$ to $0.63 \mathrm{~m} . \mathrm{s}^{-2}$ \\
Comfortable & Less than $0.315 \mathrm{~m} . \mathrm{s}^{-2}$ \\
\hline
\end{tabular}

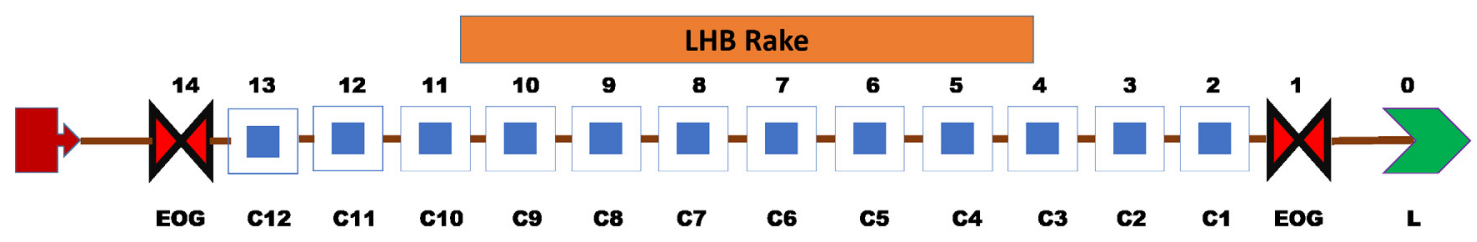

Fig. 4. Positions of cars in train model.

Lock couplers having balanced type draft gear. Moreover, the train involves a total of 14 coaches and a locomotive. The configuration for both the train with the position of locomotive and coaches are shown in Figure 4. Where L stands for the locomotive, C1-C12 are AC double decker chair car and EOG is generator/luggage van. However, the parameters of train, i.e. code and weight were given in Table 6 [19].

\subsection{Track conditions}

In this analysis, a track between Mumbai to Ahmedabad of Indian Railway was selected. The track length is about $492.7 \mathrm{~km}$ long, and has a maximum grade of two percent. The track is very straight hence the track curvature does not have much influence in the analysis. The track elevation is shown in Figure 5 [19].

\subsection{An overview of the Universal Mechanism Tool}

In this paper, a program package "Universal Mechanism" was utilised to carry out the analysis, which was designed to automate the analysis of mechanical objects and represented as a multibody system (MBS) [20]. Within such systems, bodies represented as rigid objects were linked by means of kinematic and force elements. The universal mechanism was facilitated with friendly user interface modelling and analysis. The locomotives and coaches in the model were arranged according to train configuration shown in Figure 4 . The train configured as WAP-7 locomotive having Co-Co, Fabricated Flexicoil Mark IV bogies, Double decker coaches, and generator/luggage van were shown in Figure 6a and another train which involves WAP-5 locomotive having Bo-Bo, Henschel Flexifloat bogie was shown in Figure $6 \mathrm{~b}$.

In the universal mechanism, the PARK solver was used for the simulation of the longitudinal train vehicle dynamics. Moreover, the selection of the solver was made by comparing rational parameters of different solvers. The error tolerance in the case of Park solver is $4 \mathrm{E}-6$ to $1 \mathrm{E}-$ 7 and the time step size was 0.02 s. Moreover, it was recommended to set zero value for the minimal step size for accurate analysis, but it increases the computational cost [21]. PARK was an implicit solver of the second order with a variable step size which was much more efficient both for ODE and DAE than another solver [21].

\subsection{Model validation}

To validate the locomotive model an experimental case study was taken into consideration which was tested by RDSO. In that experiment, a test trail was conducted with 24-coach 1430 tonne passenger rake for acceleration and deceleration rate [1].

The trail concluded that WAP-7 could accelerate quicker than WAP-5. If the WAP-7 was operated on a $25 \mathrm{~km}$ route then it would be able to attain the speed of $0-110 \mathrm{~km} . \mathrm{h}^{-1}$ in $240.1 \mathrm{~s}$ as compared to $312.1 \mathrm{~s}$ of WAP-5. Also, WAP-7 reaches $120-130 \mathrm{~km} \cdot \mathrm{h}^{-1}$ in $393.8 \mathrm{~s}$ as compared to WAP-5 which achieves that speed in $556.2 \mathrm{~s}$ as shown in Table 7 [1].

On the other hand, WAP-7 takes $200 \mathrm{~s}$ to reach 0$110 \mathrm{~km} \cdot \mathrm{h}^{-1}$ and $333.32 \mathrm{~s}$ to reach $0-130 \mathrm{~km} \cdot \mathrm{h}^{-1}$ as compared to WAP-5 which took $287.9 \mathrm{~s}$ and $535.2 \mathrm{~s}$ respectively using Universal Mechanism. The difference in the observations of the simulation analysis was primarily attributable to the consideration of various factors in the $\mathrm{x}$-axis only, whereas in the experimental analysis factors such as track irregularity, suspension forces, etc. were considered in all the direction. That led to an emergence of an opportunity for the LTD simulations which could be validated through comparative studies by keeping the same conditions as RDSO has kept in its test trail. The result showed that there was a good agreement between the measured data and the simulated results. Moreover, for acceleration validation, the numerical simulation is compared with the simulation from the Universal Mechanism. The train model with loco +2 coaches is taken for the analysis. The distribution of acceleration developed in the 
S.K. Sharma and A. Kumar: Mechanics \& Industry 18, 222 (2017)

Table 6. Types of Coaches and their respective weight [12].

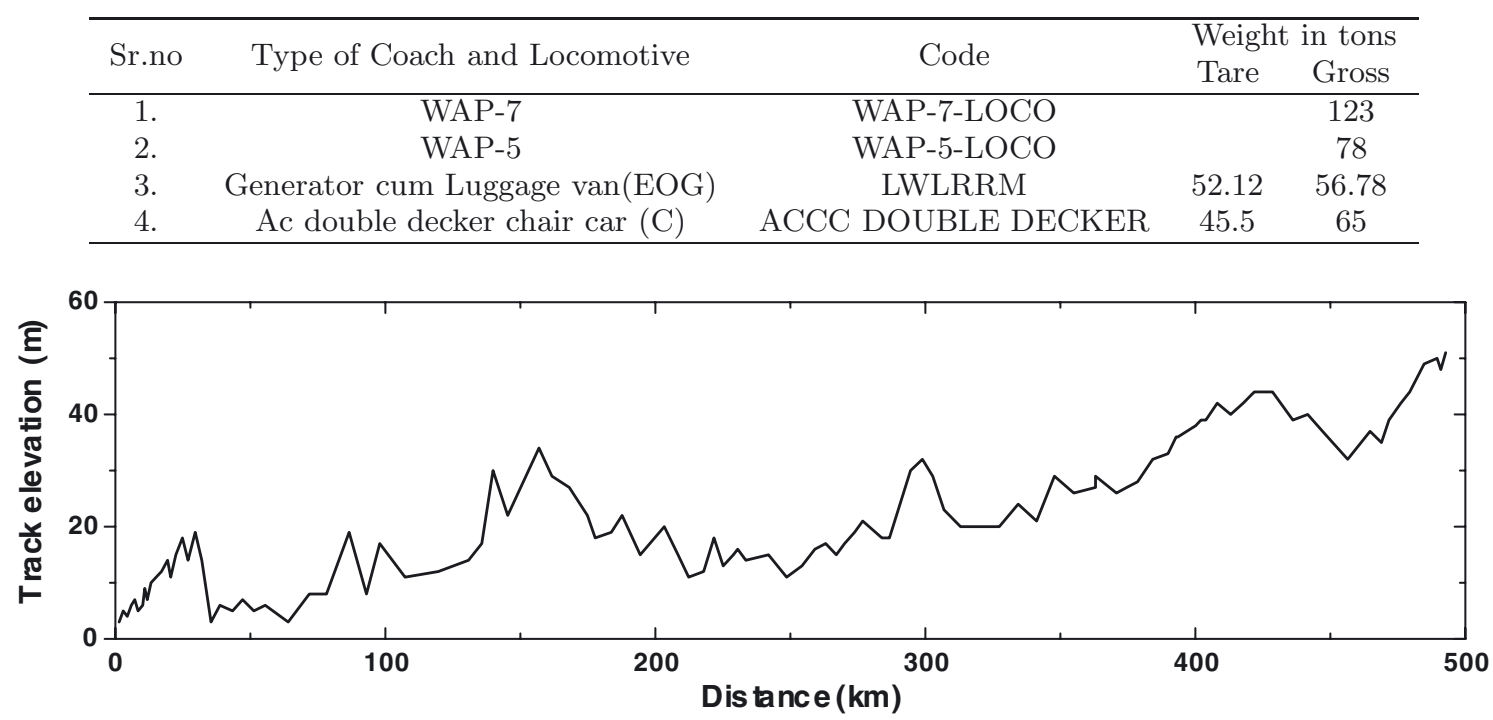

Fig. 5. Track elevation of Mumbai to Ahmedabad [19].

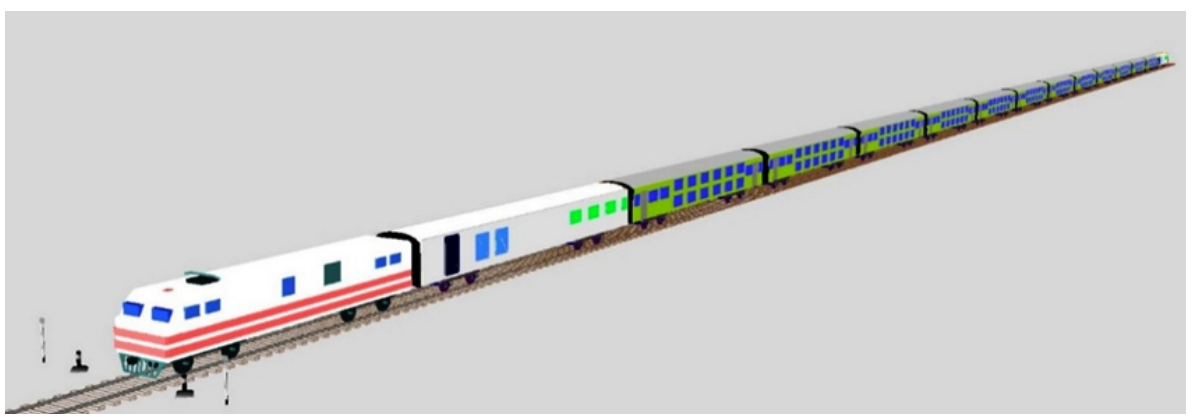

(a)

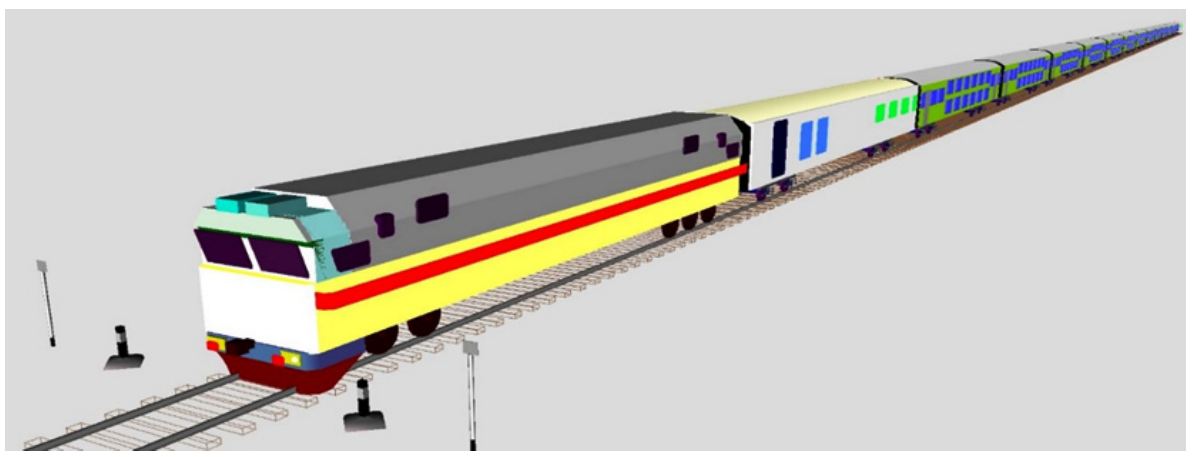

(b)

Fig. 6. (a) Model of train 1: WAP-5, double decker and Generator/language van. (b) Model of train 2: WAP-7, double decker and Generator/language van.

Table 7. Accelerate comparison of the WAP-7 and WAP-5.

\begin{tabular}{ccccc}
\hline Locomotive & $\begin{array}{c}0-110 \mathrm{~km} \cdot \mathrm{h}^{-1} \text { Time }(\mathrm{s}) \\
\text { experimentally }[1]\end{array}$ & $\begin{array}{c}0-110 \mathrm{~km} \cdot \mathrm{h}^{-1} \text { Time }(\mathrm{s}) \\
\text { simulation }\end{array}$ & $\begin{array}{c}0-130 \mathrm{~km} \cdot \mathrm{h}^{-1} \text { Time }(\mathrm{s}) \\
\text { experimentally }[1]\end{array}$ & $\begin{array}{c}0-130 \mathrm{~km} \cdot \mathrm{h}^{-1} \\
\text { simulation }\end{array}$ \\
\hline WAP-7 & 312.1 & 200 & 393.8 & 333.32 \\
WAP-5 & 240.1 & 287.9 & 556.2 & 535.2 \\
\hline
\end{tabular}




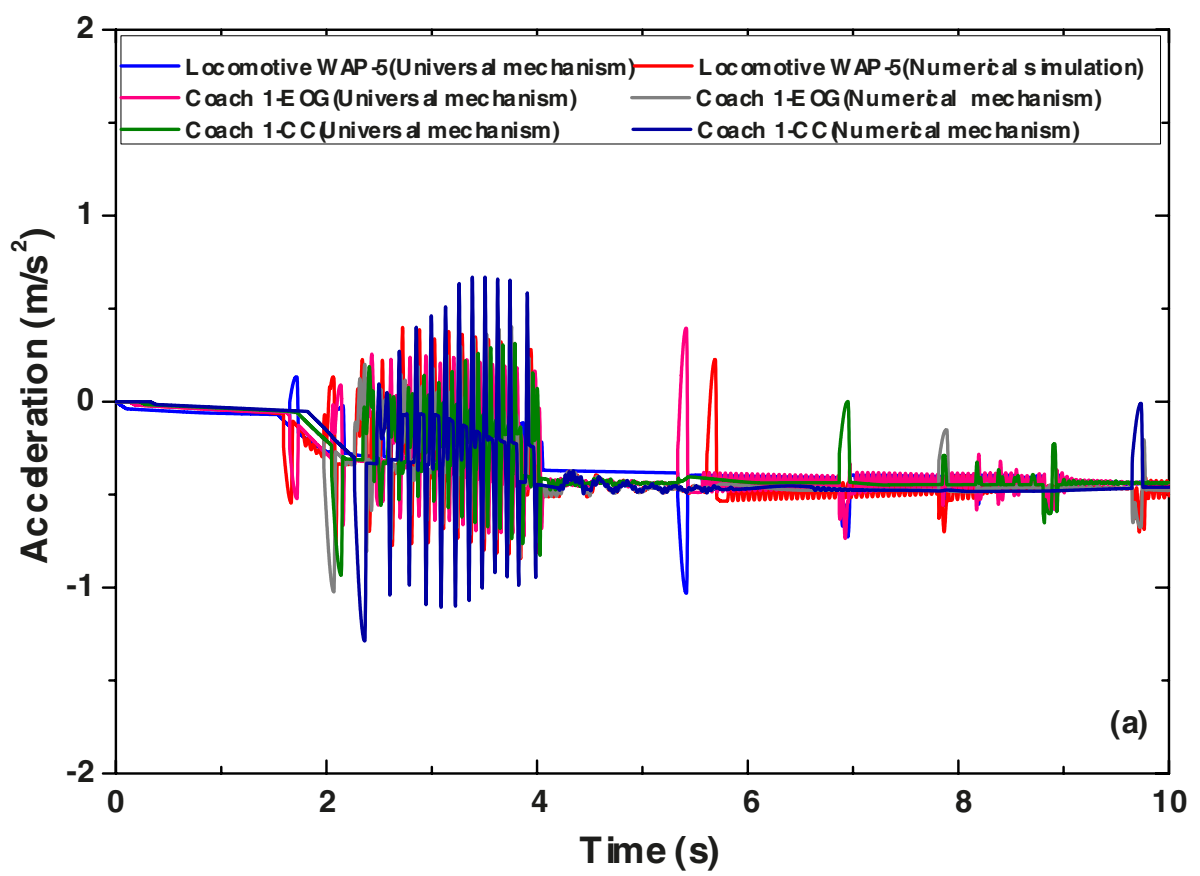

(a)

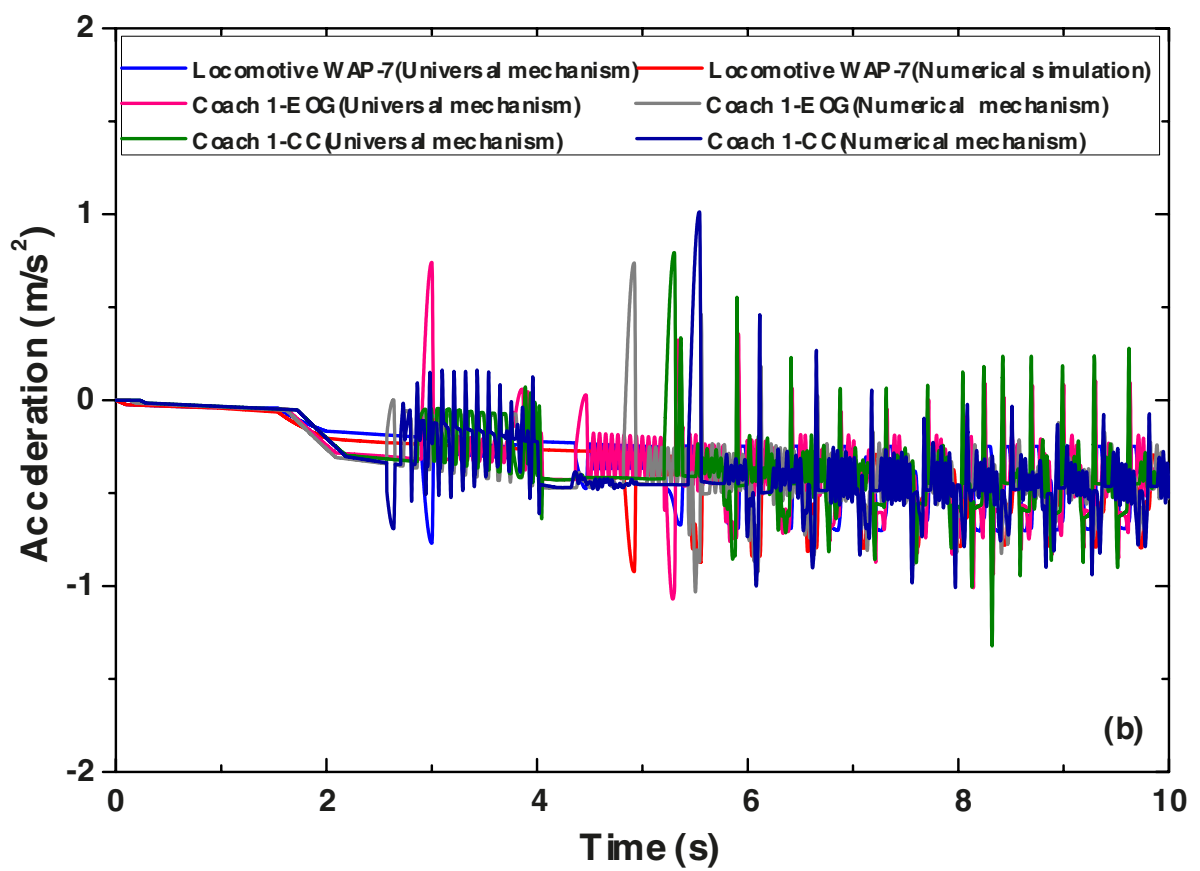

(b)

Fig. 7. Train model hauled by (a) WAP-5 (b) WAP-7.

train body is found via the braking process. In the analysis, to evaluate the acceleration, the train model which comprises of a locomotive and 2 coaches were considered under the effect of emergency braking at the initial speed of $150 \mathrm{~km} \cdot \mathrm{h}^{-1}$ as shown in Figure 1. The result based on numerical simulation is evaluated using MATLAB. Moreover, the measured acceleration from the numerical simulation is compared with the result obtained from the software for both the trains, i.e. Train 1 hauled by WAP5 and Train 2 hauled by WAP-7 as shown in Figures 7a and $7 \mathrm{~b}$.

The vehicle accelerations from the Universal Mechanism and numerical simulation showed a good agreement and were within allowable ranges. The slight variation is due to the gradient resistance force. In Indian railway, the criterion for the in-train forces of the coupler is not 
Table 8. Acceleration values at various speed.

\begin{tabular}{ccccc}
\hline & \multicolumn{2}{c}{ Locomotive WAP-5 } & \multicolumn{2}{c}{ Locomotive WAP-7 } \\
\hline Speed $\left(\mathrm{km} . \mathrm{h}^{-1}\right)$ & $a_{\text {maximum }}\left(\mathrm{m} . \mathrm{s}^{-2}\right)$ & $a_{\text {minimum }}\left(\mathrm{m} . \mathrm{s}^{-2}\right)$ & $a_{\text {maximum }}\left(\mathrm{m} . \mathrm{s}^{-2}\right)$ & $a_{\text {minimum }}\left({\left.\mathrm{m} . \mathrm{s}^{-2}\right)}^{-2}\right.$ \\
\hline 30 & 4.03 & -7.06 & 1.08 & -8.25 \\
45 & 4.86 & -7.56 & 1.13 & -0.36 \\
60 & 4.53 & -8.71 & 1.05 & -9.75 \\
90 & 3.89 & -8.67 & 2.6 & -6.94 \\
120 & 4.02 & -7.83 & 3.55 & -7.22 \\
150 & 6.94 & -7.74 & 4.83 & -7.21 \\
180 & 10 & -7.73 & 3.12 & -4.96 \\
\hline
\end{tabular}

Table 9. Sperling Ride quality Index of both the Train models.

\begin{tabular}{ccccccccc}
\hline \multirow{2}{*}{ Sr.No } & \multirow{2}{*}{ Locomotive } & \multirow{2}{*}{30} & 45 & 60 & 90 & 120 & 150 & 180 \\
\hline 1 & WAP-5 & 2.091 & 2.494 & 2.618 & 2.713 & 2.781 & 2.839 & 2.879 \\
2 & WAP-7 & 2.408 & 2.567 & 2.529 & 2.548 & 2.750 & 2.816 & 2.789 \\
\hline
\end{tabular}

larger than $1600 \mathrm{kN}$ and acceleration not larger than $1 \mathrm{~g}$ $\left(9.8 \mathrm{~m} . \mathrm{s}^{-2}\right)$. The simulated results are well below these dynamic performance limits. Therefore, it could conclude by saying that the software can be used for longitudinal train simulations.

\section{Result and discussion}

\subsection{Simulation condition}

The simulation was carried out at different initial speeds for both the locomotives, i.e. 30, 45, 60, 90, 120,150 and $180 \mathrm{~km} \cdot \mathrm{h}^{-1}$ for evaluating the behaviour via acceleration variation and autocorrelation coefficient. Nevertheless, time domain data was analysed and it was further processed through an FFT spectrum in order to obtain the ride comfort inclusive of quality in the longitudinal direction of the vehicle. The performance of the vehicle was distinct depending on the track conditions due to rail wheel interactions in the dry as well as wet contact, track elevations, track irregularities and tractive and braking effort of the locomotive. The simulation time was of $350 \mathrm{~s}$ in which the train ran at various given speed upto $200 \mathrm{~s}$ and the emergency brake was applied to halt the train.

\subsection{Acceleration response of locomotives}

The effects of track irregularities and tractive effort at different initial speed were obtained and further they were considered as input parameters for calculating rate of change of acceleration. The comparison of acceleration and the response of the vehicle is mentioned in Figures 8a$8 \mathrm{~g}$. Moreover, the longitudinal acceleration and deacceleration for both the locomotives were given in Table 8 .

The acceleration response depicted that the rate of change of velocity of WAP-5 was more than that of WAP7 in the initial velocity of $30 \mathrm{~km} \cdot \mathrm{h}^{-1}$ and $45 \mathrm{~km} \cdot \mathrm{h}^{-1}$. In contrast WAP-7 showed more ripples at a speeds of
$60 \mathrm{~km} \cdot \mathrm{h}^{-1}, 90 \mathrm{~km} \cdot \mathrm{h}^{-1}, 120 \mathrm{~km} \cdot \mathrm{h}^{-1}, 150 \mathrm{~km} \cdot \mathrm{h}^{-1}$ and $180 \mathrm{~km} \cdot \mathrm{h}^{-1}$. However, there was huge retardation in the signal after $200 \mathrm{~s}$ which was due to the emergency brakes when applied to stop the train. WAP-7 possess a better acceleration rate above the speed of $60 \mathrm{~km} \cdot \mathrm{h}^{-1}$. Nevertheless, the acceleration was generally within an acceptable range and does not show any instability at a given speed.

\subsection{Autocorrelation analysis}

Figure 9 represents the autocorrelation function for the acceleration which revealed that WAP-5 has more randomness in the signal at initial speeds of 30 and $45 \mathrm{~km} \cdot \mathrm{h}^{-1}$. On the other hand, WAP-7 has more ripples at these initial speeds of $60,90,120,150$ and $180 \mathrm{~km} \cdot \mathrm{h}^{-1}$. Thus, it could be said that above $60 \mathrm{~km} . \mathrm{h}^{-1}$, WAP-7 has rapid acceleration and deceleration as per the given condition.

\subsection{Ride quality and comfort evaluation}

Ride index of passenger trains with respect to Sperling ride index and ride comfort was evaluated by ISO 2631:1997 using MATLAB. Ride quality and comfort values have been calculated with the help of weighted r.m.s acceleration response of the vehicle. Sperling ride index values have been calculated using the Sperling formula. The acceptance criteria adopted by Indian Railway was having a maximum Sperling ride index of 3.5 at $180 \mathrm{~km} \cdot \mathrm{h}^{-1}$ vehicle speed.

In the analysis, Sperling ride Index and ISO2631 suggested values well within the quality and comfort level for both the locomotives under consideration. However, it was observed that in terms of ride quality and ride comfort WAP-7 showed better agreement at all varying speeds compared to WAP-5 at and above $60 \mathrm{~km} . \mathrm{h}^{-1}$ whereas WAP-5 showed better results at the speed of 30 and $45 \mathrm{~km} \cdot \mathrm{h}^{-1}$. That is to say, WAP-7 showed better performance after $60 \mathrm{~km} \cdot \mathrm{h}^{-1}$. The Sperling ride index and ISO ride comfort obtained are given in Tables 9 and 10 . 
S.K. Sharma and A. Kumar: Mechanics \& Industry 18, 222 (2017)

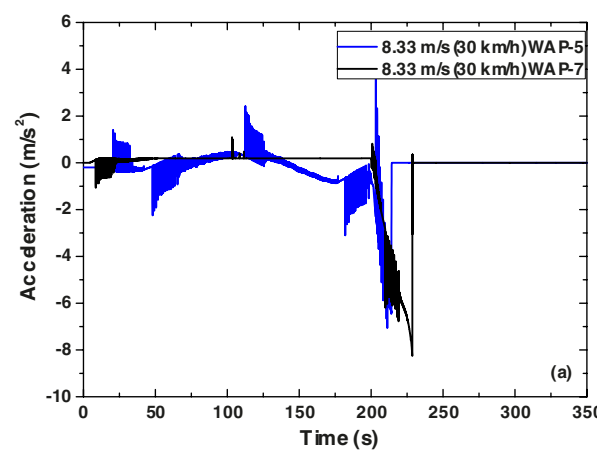

(a)

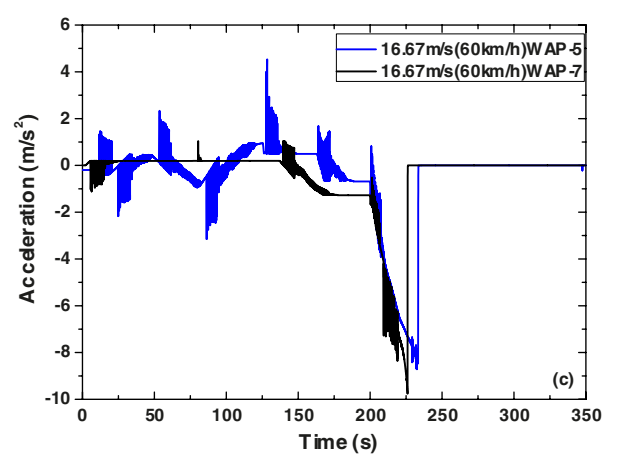

(c)

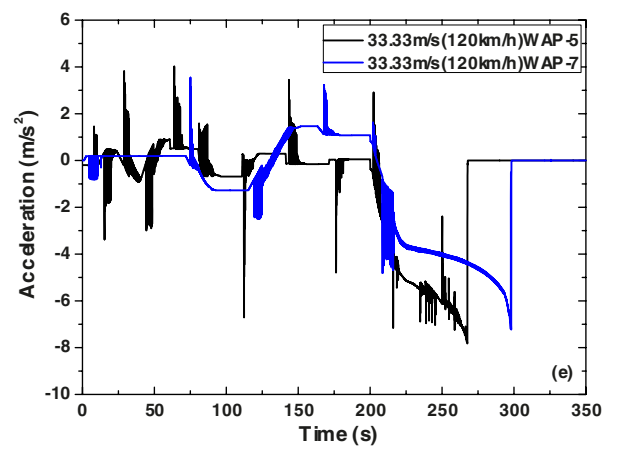

(e)

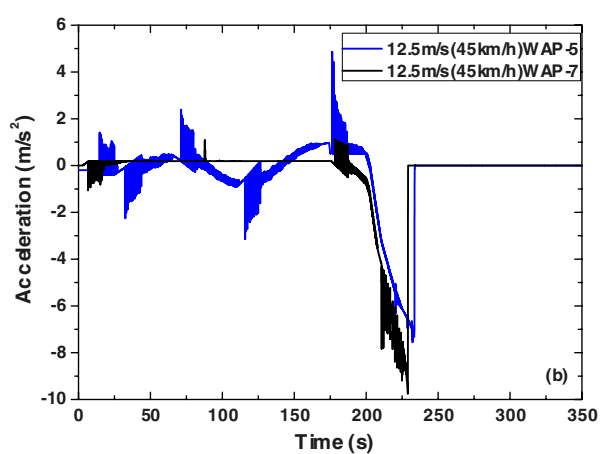

(b)

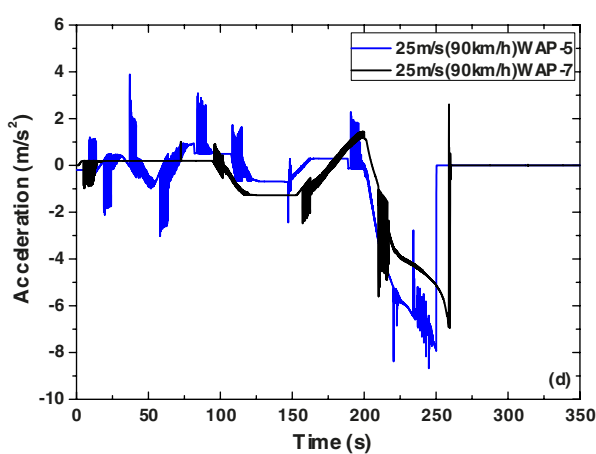

(d)

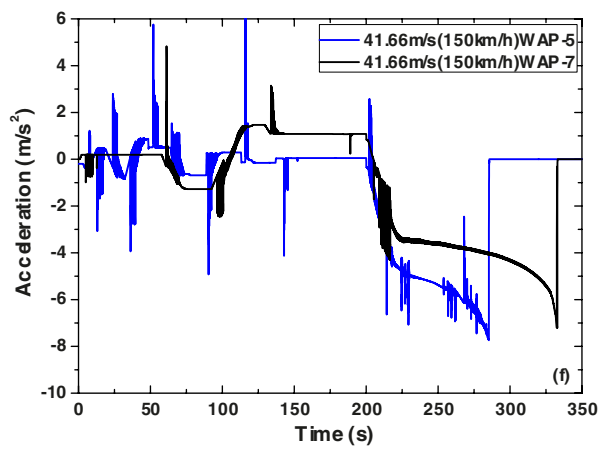

(f)

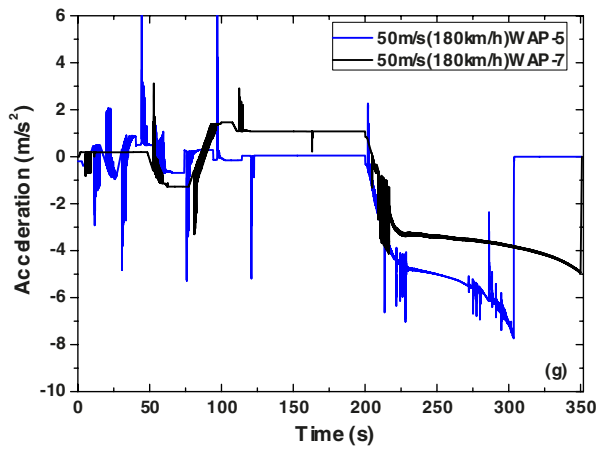

(g)

Fig. 8. Vehicle acceleration at speed (a)-(g): 30, 45, 60, 90, 120, 150, $180 \mathrm{~km} \cdot \mathrm{h}^{-1}$ respectively. 
Table 10. Ride comfort evaluation (ISO 2631) of both the train models.

\begin{tabular}{cccc}
\hline \multirow{2}{*}{ Speed km.h ${ }^{-1}$} & Locomotive WAP-5 & Locomotive WAP-7 & \multirow{2}{*}{ Ride comfort evaluation } \\
\cline { 2 - 3 } & $a_{\mathrm{wrms}}$ & $a_{\mathrm{wrms}}$ & \\
\hline 30 & 0.083 & 0.132 & comfortable \\
45 & 0.149 & 0.164 & comfortable \\
60 & 0.175 & 0.156 & comfortable \\
90 & 0.197 & 0.160 & comfortable \\
120 & 0.214 & 0.206 & comfortable \\
150 & 0.229 & 0.223 & comfortable \\
180 & 0.240 & 0.216 & comfortable \\
\hline
\end{tabular}

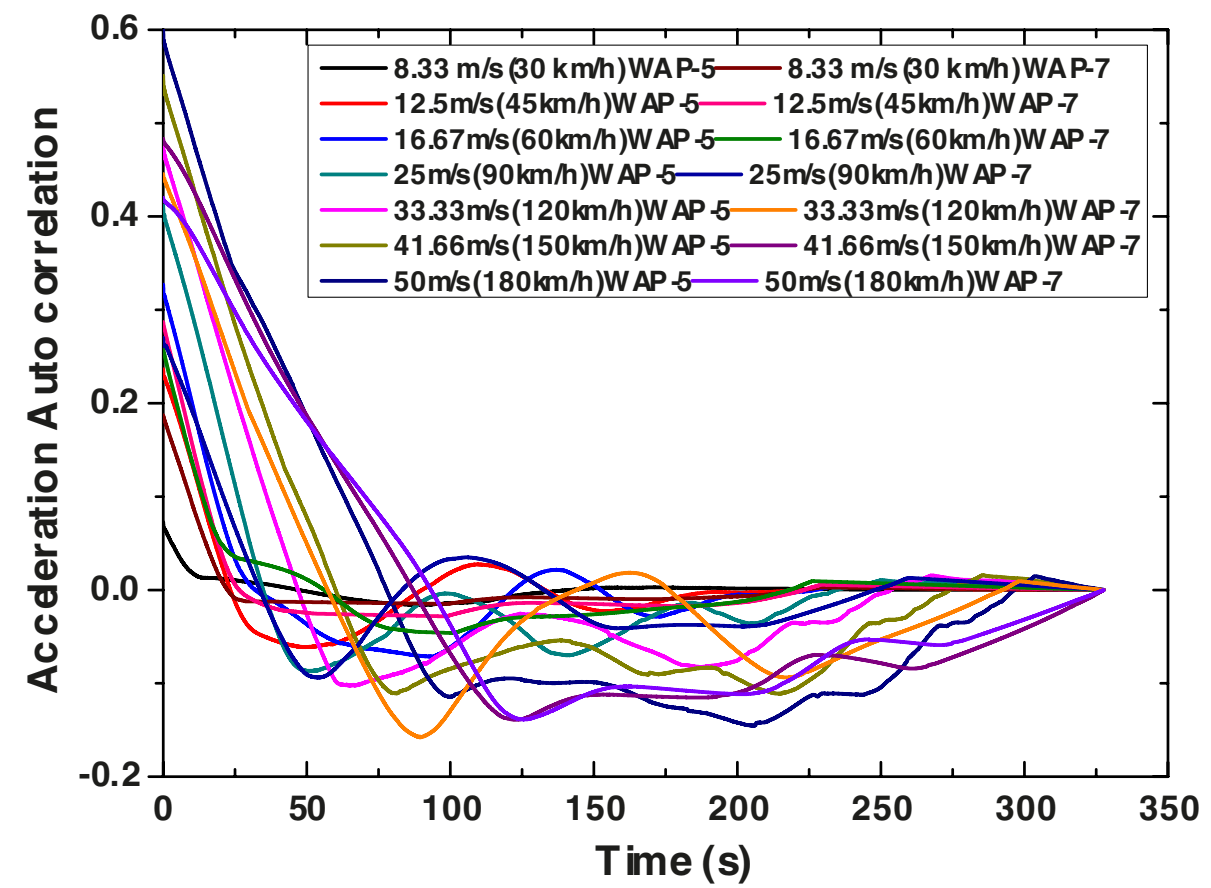

Fig. 9. Autocorrelation analysis for the acceleration at different initial speed.

\section{Conclusion}

The analysis of longitudinal train dynamic was done to evaluate the ride quality and ride comfort. In this paper, a comparative analysis was done between WAP-5 and WAP-7 electric locomotives. Rail track corridor between Mumbai to Ahmedabad (India) was taken into consideration. The effect due to TE, BE and variation in the initial speeds, i.e. $30,45,60,90,120,150$ and $180 \mathrm{~km} . \mathrm{h}^{-1}$ were analysed, keeping all the other parameters constant. In the suggested analysis, Sperling ride index and ISO2631 suggested values were within the quality and comfort level for both the locomotives under consideration. However, it can be observed in the analysis in terms of ride quality and ride comfort, WAP-7 has shown better agreement at all varying speeds compared to WAP-5 at and above $60 \mathrm{~km} . \mathrm{h}^{-1}$ whereas WAP-5 performed better at the speed of 30 and $45 \mathrm{~km} \cdot \mathrm{h}^{-1}$. It can be concluded from the analysis that WAP-7 performs better above $60 \mathrm{~km} \cdot \mathrm{h}^{-1}$.

\section{References}

[1] Electric Locomotive Classes - AC WAP7 and WAP5, 2009, http://www.irfca.org/faq/faq-loco2e.html (accessed 19 May 2016)

[2] S. Pitroda, D. parekh, M. S. Verma, R. Lall, G. Raghuram, V. Chatterjee, R. Jain, Report of the Expert Group for Modernizaion of Indian Railways, Ministry of Railways, Government of India 2012

[3] Indian locomotive class WAP-5, 2015; https://en. wikipedia.org/wiki/Indian_locomotive_class_WAP-5 (accessed 03 July 2015)

[4] Indian locomotive class WAP-7, 2015 https://en. wikipedia.org/wiki/Indian_locomotive_class_WAP-7 (accessed 03 July 2016)

[5] C. Colin, Longitudinal Train Dynamics, Handbook of Railway Vehicle Dynamics, CRC Press 2006, pp. 239-277

[6] Q. Wu, S. Luo, C. Cole, Longitudinal dynamics and energy analysis for heavy haul trains, J. Modern Trans. 22 (2014) 127-136 
[7] Y. Sun, C. Cole, M. Spiryagin, T. Godber, S. Hames, M. Rasul, Longitudinal heavy haul train simulations and energy analysis for typical Australian track routes, Proceedings of the Institution of Mechanical Engineers, Part F: Journal of Rail and Rapid Transit 228 (2013) 355-366

[8] L. F. Shampine, Vectorized adaptive quadrature in MATLAB, J. Comput. Appl. Mathem. 211 (2008) 131140

[9] C. Crăciun, T. Mazilu, Simulation of the longitudinal dynamic forces developed in the body of passenger trains, Ann. Faculty Eng. Hunedoara - Int. J. Eng. 12 (2014) 19-26

[10] C. Cruceanu, Train Braking, Reliability and Safety in Railway, Dr. Xavier Perpinya (Ed.), InTech, 2012 .DOI: 10.5772/37552. Available from: http://www . intechopen.com/books/reliability-and-safety-inrailway/braking-systems-for-railway-vehicles

[11] M. K. Jain, Train, grade, curve and Acceleration Resistance, 2013; https://www.railelectrica. com/traction-mechanics/train-grade-curve-andacceleration-resistance-2/ ( accessed 12 December 2015)

[12] K. Chandra, Maintenance manual for BG coaches of LHB design, Ministry of Railways, Government of India 2002

[13] A. Swaroop, A technical note in continuation of a reasoned document of EOI of AAR 'H'Type tight-lock couplers having balanced type draft gear, Research Designs and Standards Organisation, 2011

[14] WAP-5 and WAP-7 tractive effort / braking effort, Technical Data and Notes, Indian Railways, India, 2001. http://www.irfca.org/docs/index.html\# tech (accessed 10-oct, 2015)

[15] M. Haag, Autocorrelation of Random Processes, Charlet Reedstrom, OpenStax Rice University, 2005 https:// cnx.org/contents/cillqc8i@5/Autocorrelation-ofRandom-Proc. (accessed 20 May 2016)

[16] T. M. Apostol, Modular functions and Dirichlet series in number theory, Springer Science \& Business Media, 2012

[17] R. C. Sharma, Sensitivity Analysis of Ride Behaviour of Indian Railway Rajdhani Coach using Lagrangian Dynamics, Int. J. Vehicle Struct. Sys. 5 (2013) 84-89

[18] Y.-T. Fan, W.-F. Wu, Dynamic analysis and ride quality evaluation of railway vehicles numerical simulation and field test verification, J. Mech. 22 (2006) 1-11

[19] 12931/mumbai central-Ahmedabad AC double decker express Indian rail info, Indian rail info, 2014.; http://indiarailinfo.com/train/mumbai-centralahmedabad-ac-double-decker-express-12931-bctto-adi/18711/297/60 ( accessed 10 October 2015)

[20] Universal Mechanism software, 2015. http://www. universalmechanism.com/ (accessed 15 September 2015)

[21] Simulation of rail vehicle dynamics user's manual Universal Mechanism 7.0 2014 